\title{
Staying On or Dropping Out? The Role of Intergroup Friendship and Perceived Teacher Support in Minority and Nonminority School Careers
}

\author{
GÜLSELI BAYSU \\ KAREN PHALET \\ University of Leuven
}

Background: Bridging educational and social psychology, we examine the impact of positive intergroup relations in schools on minority and nonminority school careers.

Purpose of Study: The study aims to estimate and explain the attainment gap between Turkish Belgian minority and Belgian nonminority students at four stages of their school careers, controlling for family background and prior attainment. Intergroup friendship and perceived teacher support were expected to reduce the attainment gap.

Research Design: Randomly sampled Turkish Belgian students and students in a nonminority comparison sample $(N=661)$ answered retrospective questions on their school careers and early schooling experiences. By way of separate multinomial logistic regressions, we estimated the attainment gap as the odds of leaving school or staying in vocational (vs. academic) education at four stages: lower, middle, upper secondary, and tertiary levels. Next, we tested the effects of intergroup friendship and teacher support on track placement and dropout at each level.

Results: As expected, our findings indicated a persistent and widening attainment gap between minority and nonminority school careers in the hierarchical structure of the Belgian school system. Minority students who had started in academic tracks were less likely to continue in academic and higher education and more likely to leave school at each stage than similar nonminority students. Intergroup friendship (for minority students) and perceived support from teachers (for all) significantly increased staying-on rates and reduced the attainment gap. 
Conclusion: Our findings demonstrate the key role of positive intergroup relations with peers and teachers in enabling students, especially minority students, to stay on in school.

The children of immigrant workers from less developed countries ${ }^{1}$ are typically underrepresented in academic and higher education in the United States (Kao \& Thompson, 2003) and in Europe (Heath, Rothon, \& Kilpi, 2008). In addition to their initial disadvantage in early school achievement, they often have higher dropout risks in secondary school and lower chances to stay on in higher education. For example, less advantaged Hispanic minority students in the United States (Kao \& Thompson) and Turkish minority students in Europe (Heath et al.) are consistently lagging behind majority or White students in terms of early school achievement and later attainment levels.

This article's empirical focus is on the educational disadvantage of the Turkish second generation in Belgium as an exemplary case of persistent educational disadvantage among the European-born children of immigrant workers (Heath et al., 2008; Phalet \& Heath, 2011). The majority of Turkish Belgian students are in vocational training; they are more at risk of dropping out without completing secondary education; and they have less chance to obtain higher qualifications (Phalet, Deboosere, \& Bastiaenssen, 2007). Neither the critical junctures nor the processes behind their educational disadvantage, however, have been clearly established. Accordingly, the first research aim is to identify the critical junctures where minority and nonminority school careers tend to diverge. To this end, the study describes how the gap between minority and nonminority attainment levels unfolds over time at four successive stages during secondary school and beyond.

In the Belgian school system, as in other European systems with hierarchical tracking structures, attainment is most reliably measured by differential track placement and dropout status at successive stages of the school career. ${ }^{2}$ The Belgian educational system has a fairly rigid hierarchical tracking structure, which allocates students to academic or vocational types of tracks at entry into secondary school (at the normative age of 12) while allowing some (mainly downward) mobility between tracks in later years. Academic tracks prepare students for tertiary education, whereas vocational tracks lead directly to the labor market. In today's postindustrial economies, however, vocational qualifications have become increasingly disconnected from access to stable and well-paid jobs, and they offer little protection from unemployment or economic inactivity (Phalet \& Heath, 2011). 
For disadvantaged minority groups, especially in hierarchically structured school systems like the Belgian system, several longitudinal studies have reported increasing achievement and attainment gaps in the course of secondary school (for track placement, Dauber, Alexander, \& Entwisle, 1996; for dropout risks, Kalmijn \& Kraaykamp, 2003; for math and reading scores, Moller, Stearns, Blau, \& Land, 2006). Neither differential parental resources nor individual differences in academic knowledge and motivation fully explain why the attainment gap between minority and nonminority students increases in the course of the school career, nor do we know why some minority students persist in academic tracks and stay on in school longer, whereas many others with similar parental backgrounds and entry levels do not (Phalet et al., 2007; Walberg, Fraser, \& Welch, 1986).

Turning to the school environment as an alternative explanatory ground of differential attainment, and looking beyond formal tracking structures, we argue that schools may be less effective in supporting adaptive learning for minority students, even in the absence of overt prejudice or discrimination (Purdie-Vaughns, Steele, Davies, Ditlmann, \& RandallCrosby, 2008). Combining perspectives from social and educational psychology and focusing on possible protective factors in the school context, our second research aim is therefore to identify critical relational features of a supportive learning environment for minority and nonminority students. Specifically, this study sets out to examine the role of perceived teacher support and intergroup friendship in the early school environment, taking into account ethnic school composition, in explaining (part of) the attainment gap at later stages. Finally, in light of more restricted resources in disadvantaged immigrant families, minority students may profit more from a supportive school environment than nonminority students (Han, 2008; Murray, 2009; Phelan, Davidson, \& Yu, 1998; Suárez-Orozco, Pimentel, \& Martin, 2009; Wentzel \& Wigfield, 2007). Therefore, we ask the additional question, whether positive relational experiences with intergroup friends and with teachers have stronger protective effects for minority students.

To address our central research questions about minority and nonminority school careers and schooling experiences, we draw on retrospective survey data from a large random sample of the Turkish Belgian second generation and a matched comparison sample of nonminority Belgians in the city of Antwerp. Turkish labor migration to the northwest of Europe, including Belgium, goes back to the late 1960s and early 1970s. Turkish "guest workers" were recruited from less socioeconomically developed rural parts of Turkey to be employed in semi- or unskilled 
manual work. From the early 1980s onward, family reunion and formation policies enabled the permanent settlement of Turkish immigrant families and communities. At the same time, the postindustrial transition relegated large portions of immigrant workers to enduring unemployment and economic inactivity. The children of Turkish immigrant workers, who are now leaving school and entering the labor market, are one of the most educationally disadvantaged groups internationally (Heath et al., 2008), and ethnic educational disparities in Belgium are among the largest in Europe (Phalet et al., 2007). Together, the cross-national findings of increased dropout risks and restricted access to higher education for the Turkish second generation and the relatively large ethnic inequalities in the Belgian school system in comparative perspective (Organisation for Economic Co-operation and Development [OECD], 2006; Phalet et al., 2007) make the Turkish Belgian case a strategic research context for our purposes.

\section{MINORITY AND NONMINORITY SCHOOL CAREERS}

Disadvantaged minority students are most often lagging behind their nonminority peers in school. In some cases, minority educational disadvantage was even found to increase rather than decrease in the course of the school career (Dauber et al., 1996; Moller et al., 2006). For instance, Turkish, Moroccan, and Caribbean minority students were less likely to stay on in secondary school compared with nonminority Dutch students (Kalmijn \& Kraaykamp, 2003). In particular, minority students who failed would drop out sooner, whereas nonminority students who failed more often continued in a different track. Although family-based resources and prior school performance typically explain a large part of minority disadvantage, differences often remain significant for disadvantaged minority groups, such as the Turkish group (Heath et al., 2008; Kalmijn \& Kraaykamp, 2003).

Building on solid evidence of persistent Turkish disadvantage, the first aim of our study is to describe this disadvantage at four successive stages of the school career. To this end, we trace track placement and dropout status of Turkish minority students in comparison with most similar nonminority students throughout secondary school and beyond. Specifically, detailed retrospective data on minority and nonminority school careers allow precise estimations of the net attainment gaps at the lower, middle, and upper secondary levels and at the tertiary level. The analyses show whether the attainment gap decreases, persists, or increases in the course of minority (vs. nonminority) school careers. In particular, an increasing gap, as suggested by some earlier studies, would 
imply that even academically successful Turkish minority students (i.e., those who were not retained in primary school and who started secondary school in academic tracks) are less likely to stay on in school than nonminority students, after controlling for individual and family background. If we find evidence of an increasing attainment gap, our second research aim is to explain why even high-achieving minority students would be less able to stay on in academic and higher education than nonminority students.

Turning to relational features of ethnically diverse school contexts as a possible explanatory ground, we use an identity safety (vs. threat) approach of minority performance in mainstream settings as a heuristic framework. From the perspective of social identity theory (Tajfel \& Turner, 1986), direct or vicarious experiences of discrimination or negative stereotyping may induce identity threat in members of devalued minority groups. In school contexts, perceived identity threat was found to decrease the academic engagement and performance of minority group members (Derks, van Laar, \& Ellemers, 2007; Purdie-Vaughns et al., 2008). For example, there is longitudinal evidence associating perceptions of discrimination in school with impaired school adjustment and achievement among minority students (Benner \& Kim, 2009). Similarly, perceived discrimination in school was associated with academic disidentification among Turkish Dutch students (Verkuyten \& Thijs, 2004). In parallel, salient negative stereotypes of a group's competence were shown to undermine the performance of stereotyped group members (Steele, Spencer, \& Aronson, 2002, for experimental evidence of "stereotype threat"; see also Massey \& Fischer, 2005, for longitudinal evidence).

Finally, also in the absence of overt prejudice and discrimination, academic settings may expose minority group members to identity threat whenever (subtle) situational cues convey the message that their group is less valued than the majority group (Derks et al., 2007; Purdie-Vaughns et al., 2008). One very simple diagnostic cue of identity safety (or threat) is the presence (or absence) of fellow minority group members in an academic setting. For example, Turkish Belgian university students find themselves in an academic environment with very few, if any, minority students or teachers. As they climb the educational ladder and venture into more exclusive mainstream settings, minority group members are thus increasingly exposed to identity threat (Derks et al.; Purdie-Vaughns et al.; Walton \& Cohen, 2007). To conclude, in the presence of widespread negative stereotypes of Turkish academic competence (Kleinpenning \& Hagendoorn, 1991) and in the near absence of images or messages valuing the Turkish identity in the academic domain, it 
follows that for Turkish minority students, identity threat is "in the air" they breathe (Steele, 1997; for Turkish Belgians, see also Baysu, Phalet, \& Brown, 2011). Against this background of pervasive identity threat, the explanatory focus of our study is on the quality of intergroup contact with peers and teachers as a source of identity protection.

From the perspective of social identity theory, so-called social identity protection is essential in the creation of supportive learning environments for minority students in particular. Social identity protection requires that the school context effectively communicates to minority students that their minority identity is accepted and valued in school. For example, African American students were more sensitive than White students to the perceived quality of their relationships with other students and professors, which they perceived as diagnostic of their academic value and belonging (Walton \& Cohen, 2007). Accordingly, the present study focuses on perceived teacher support and intergroup friendships as indicative of the quality of students' relationships with teachers and peers. Perceived teacher support is known from research in educational psychologists as a generic protective factor, which has been associated with sustained academic engagement and performance (Hamre \& Pianta, 2001). In addition, from an identity safety approach in social psychology, intergroup friendship may be particularly important for the school engagement of minority students (Shook \& Fazio, 2008).

\section{INTERGROUP FRIENDSHIP}

When we find evidence of a persistent or widening attainment gap, the next question is which critical protective factors may reduce the gap by making the school environment less threatening or more supportive for minority students. Research on intergroup contact theory documents robust associations of positive experiences of intergroup contact with favorable intergroup attitudes for minority and majority members (Brown \& Hewstone, 2005; Pettigrew \& Tropp, 2006). Intergroup friendship in particular positively predicts more favorable attitudes in intergroup relations as well as increased school adjustment and achievement (Hallinan \& Williams, 1990; Shook \& Fazio, 2008). In addition, there are good reasons to expect that Turkish Belgian students will benefit more from intergroup friendship (i.e., friendship with majority group students).

First, students' minority status implies that their relationships with peers and teachers are defined not only as interpersonal encounters but also as positive or negative contact with majority group members (Brown \& Hewstone, 2005). Therefore, intergroup friendships might signal to minority students that the majority group accepts and values diversity. 
Accordingly, when the majority group valued their identity, minority group members were more motivated to perform well (Derks et al., 2007). Second, intergroup friends provide opportunities to learn about intergroup similarities, rather than differences, and to disconfirm negative beliefs and feelings (Shook \& Fazio, 2008). Thus, they may shield minority students from known disruptive effects of identity threat in school. Accordingly, stereotype threat research shows that both contact (Abrams, Eller, \& Bryant, 2006) and addressing similarities across ingroup and outgroup members (Rosenthal, Crisp, \& Suen, 2007) reduce stereotype threat and increase performance.

Third, to the extent that Belgian friends facilitate culture learning, Turkish Belgian students will benefit from language learning and the acquisition of culturally grounded knowledge and behavioral repertoires, which are typically valued in the school context and generally lacking in immigrant families (Ward, Bochner, \& Furnham, 2001). Accordingly, acculturation studies show that minority students who are more oriented toward the majority culture are better adjusted and more high achieving than those with a more exclusive orientation toward the minority culture (Berry, Phinney, Sam, \& Vedder, 2006).

In parallel, sociologists have documented positive effects of intergroup contact as a source of "bridging social capital" on a range of individual outcomes, including school attainment (Portes, 1998). Positive effects are generally explained by the fact that contact across group boundaries gives access to valuable resources that may be lacking in the minority ingroup (Kalter, 2006). In addition, intergroup friends may provide minority students with effective role models of school adjustment. Accordingly, students' individual motivation and achievement have been found to mirror those of their peer group (Hallinan \& Williams, 1990; Harris, 2010; Ryan, 2001).

Taken together, these different strands of research suggest that intergroup friendship may help minority students to adjust more smoothly to a predominantly nonminority school environment. Accordingly, we expect that Turkish Belgian students will benefit most from intergroup friendship.

\section{PERCEIVED TEACHER SUPPORT}

Another critical protective factor, which has received extensive research attention in developmental and educational psychology, is the quality of student-teacher relationships. Supportive relationships with teachers, as perceived by both teachers and students, reliably predict school adjustment and achievement (Birch \& Ladd, 1997; Buyse, Verschueren, Verachtert, 
\& Van Damme, 2009; Entwisle \& Hayduk, 1988; Hughes, Cavell, \& Willson, 2001; Murray \& Greenberg, 2000; Phelan et al., 1998; Wentzel \& Wigfield, 2007). From the teacher's perspective, teachers' attitudes are found to influence student treatment in terms of judgment and grading, so that positive attitudes enhance students' self-confidence and academic performance (Hamre \& Pianta, 2001). From the students' perspective, positive relationships with teachers protect them against poor performance by enhancing school belonging and motivation for schoolwork (Goodenow, 1993). In a longitudinal study of early adolescents' academic achievement, for example, DiLalla, Marcus, and Wright-Phillips (2004) found that children with poor student-teacher relationships had lower grades in school. Although all students may benefit from supportive relationships with teachers, support from teachers is especially important for disadvantaged minority students because they are more often lacking educational resources and effective support at home (Han, 2008; Murray, 2009; Suárez-Orozco et al., 2009). Moreover, from an identity safety approach of the school environment, supportive student-teacher relationships signal the quality of intergroup relationships in school. More specifically, to the extent that teachers represent authority in school, teachers' attitudes and treatment of minority students communicate the presence (or absence) of institutional support for diversity and intergroup contact in a particular school. Therefore, we reason that perceived support from teachers will foster minority students' sense of school belonging, which may come less naturally in a predominantly nonminority environment (Suárez-Orozco et al.; Walton \& Cohen, 2007).

\section{THE PRESENT STUDY}

\section{HYPOTHESES}

To assess the attainment gap, this study examines the track placement and dropout status of the same students at four critical stages in their school careers. We tested the following hypotheses: (1) the net gap between minority and nonminority students will persist or widen in the course of the school career, controlling for family background and prior attainment; (2) the early school environment-in particular, intergroup friendship and perceived teacher support—will explain part of this gap; (3) both intergroup friendship and perceived teacher support, controlling for school segregation, will be associated with increased chances of being in academic tracks and staying on in school (main effect); and (4) the protective role of intergroup friendship and perceived support may be stronger for minority students (interaction effect). 


\section{METHOD}

\section{PARTICIPANTS}

Participants were Turkish Belgian young adults $(n=358)$, and a nonminority comparison sample $(n=303)$ in Antwerp between the ages of 18 and $35(M=25 ; S D=4.78)$ (TIES, 2008). As a world harbor, Antwerp has attracted significant numbers of immigrant workers from Turkey who were later joined by their families. As in other European cities, the Turkish immigrant community in Antwerp continues to be relatively segregated and disadvantaged. As a Muslim minority, they face widespread public prejudice and ethnic hostility, as evident from the strong presence of populist anti-immigrant parties and electorates in Antwerp. Turkish Belgian participants in our study were all second generation (i.e., they were local-born, with one or both parents born in Turkey). The minority sample was randomly drawn from the municipality register. Nonminority participants were selected from the same ethnically mixed and socioeconomically disadvantaged neighborhoods. ${ }^{3}$ Participants were visited at home by trained interviewers who conducted extensive computerassisted personal interviews using a standardized questionnaire instrument in Dutch. Parental education was lower for minority than for nonminority participants (see Table 1 for sample characteristics). Of all

Table 1. Descriptive Statistics of Predictor Variables for Turkish Belgian Minority and Belgian Nonminority Students

\begin{tabular}{|c|c|c|c|}
\hline & Turkish Belgian & Belgian & \\
\hline Categorical variables & \multicolumn{2}{|c|}{ Frequencies and within column $\%$} & Pearson $^{2}$ \\
\hline Gender & & & .04 \\
\hline Male & $178(50 \%)$ & $153(49.5 \%)$ & \\
\hline Female & $180(50 \%)$ & $150(50.5 \%)$ & \\
\hline \multicolumn{3}{|l|}{ Grade retention in primary school } & $56.66^{*}$ \\
\hline Retained & $164(46 \%)$ & $55(18 \%)$ & \\
\hline Promoted & $194(54 \%)$ & $248(82 \%)$ & \\
\hline \multicolumn{2}{|l|}{ Grade retention in secondary school } & $14.95^{*}$ & \\
\hline Retained & $182(52 \%)$ & $111(37 \%)$ & \\
\hline Promoted & $168(48 \%)$ & $190(63 \%)$ & \\
\hline \multicolumn{3}{|l|}{ Best friend } & $264.93 *$ \\
\hline Belgian & $94(26 \%)$ & $271(89 \%)$ & \\
\hline Other & $264(74 \%)$ & $32(11 \%)$ & \\
\hline \multicolumn{3}{|c|}{ Within-group means and $S D$} & $T$ \\
\hline Father's education & $1.25(.71)$ & $2.18(.70)$ & $-16.89 *$ \\
\hline Primary school segregation & $3.57(1.7)$ & $1.94(1.1)$ & $14.22 *$ \\
\hline Secondary school segregation & $3.57(1.5)$ & $2.53(1.3)$ & $9.38^{*}$ \\
\hline Belgian friends & $3.16(1.1)$ & $4.57(.84)$ & $-18.16^{*}$ \\
\hline Perceived teacher support & $4.02(.77)$ & $3.93(.71)$ & 1.61 \\
\hline
\end{tabular}


participants, $19 \%$ were full-time students at the time of the survey; $65 \%$ were employed; and the others were unemployed or otherwise economically inactive.

\section{MEASURES}

School career. Track placement and dropout status were measured by four categorical dependent variables at four stages in participants' school careers (Table 2): at entry into secondary education: vocational or academic track (reference category); at the middle and upper secondary levels: dropout, vocational track, or academic track (reference); and at entry into higher education: leaving school or continuing (reference).

Table 2. Turkish Belgian Minority and Belgian Nonminority Students at Lower, Middle, and Upper Secondary Levels and Beyond: Numbers and Percentages

\begin{tabular}{|c|c|c|c|c|}
\hline \multirow[b]{2}{*}{ Levels } & \multicolumn{2}{|c|}{ Turkish Belgian } & \multicolumn{2}{|c|}{ Belgian } \\
\hline & Frequencies & $\%$ Column & Frequencies & $\%$ Column \\
\hline \multicolumn{5}{|l|}{ 1. Lower secondary } \\
\hline Vocational track & 114 & $32.5 \%$ & 47 & $15.5 \%$ \\
\hline Academic track & 237 & $67.5 \%$ & 256 & $84.5 \%$ \\
\hline \multicolumn{5}{|l|}{ 2. Middle secondary } \\
\hline Dropout & 36 & $10 \%$ & 12 & $4 \%$ \\
\hline Vocational track & 152 & $44 \%$ & 60 & $20 \%$ \\
\hline Academic track & 159 & $46 \%$ & 230 & $76 \%$ \\
\hline \multicolumn{5}{|l|}{ 3. Upper secondary } \\
\hline Dropout & 72 & $25.5 \%$ & 22 & $8 \%$ \\
\hline Vocational track & 107 & $38 \%$ & 58 & $21 \%$ \\
\hline Academic track & 103 & $36.5 \%$ & 200 & $71 \%$ \\
\hline \multicolumn{5}{|l|}{ 4. Beyond secondary } \\
\hline Dropout & 92 & $44 \%$ & 56 & $22 \%$ \\
\hline Any type of tertiary & 119 & $56 \%$ & 202 & $78 \%$ \\
\hline
\end{tabular}


Intergroup friendship. Participants reported how many of their friends were of Belgian origin when they were between 13 and 16 years old on a 5-point scale, from 1 (none) to 5 (most). They also indicated the ethnic background of their best friend in the same period $(1=$ nonminority Belgian, $0=$ other .

Perceived teacher support. The perceived teacher support scale was constructed by taking the mean of three items ("Most of my teachers were listening to me"; "I got along with most of my teachers"; "My teachers took care of me when I needed additional help"), which were taken from the PISA study (OECD, 2006). The items formed a reliable scale with internal consistencies: $=.78$ for minority groups and .76 for nonminority groups. Items were rated from 1 (totally disagree) to 5 (totally agree), with higher scores signifying more support.

Control variables. Father's education was measured as a covariate $(0=$ less than primary; 1 = primary or lower secondary; 2 = full secondary; $3=$ tertiary level). It was highly correlated with mother's education $(r=.65)$. Language use at home was omitted from the final analyses because it had no significant effects. Gender was dummy coded $(1=$ female, $0=$ male $)$. For grade retention, participants reported retrospectively whether they had ever repeated a class in primary and secondary school $(1=$ retained, $0=$ promoted as reference). School segregation was self-reported: Participants indicated retrospectively how many children of immigrant origin attended their primary and secondary school, from 1 (almost none) to 7 (almost all).

\section{ANALYSES}

Separate binomial (for entry into secondary school and higher education) and multinominal (for transitions to middle and upper secondary school) logistic regression models were estimated at the four successive levels. Effect parameters B in logistic regression will be discussed in terms of the corresponding odds ratios and estimated probabilities (Agresti, 1996). Continuous variables were centered on the mean to avoid multicollinearity and to enhance the meaningful interpretation of coefficients. Predictors were lagged in time with outcome measures, so that only (retrospectively reported) preceding variables were included to predict outcomes at later stages. Probabilities of outcomes at the next educational level were estimated conditionally on having reached the preceding level (Breen \& Jonsson, 2000). Because cases that have dropped out of school are no longer included in the analysis at later stages, effective sample sizes decreased from one level to the next. ${ }^{4}$ This stepwise approach provides a most stringent estimate of the attainment gap and the effects of 
perceived school environment, because effective samples at later stages consisted of a more selective group of students.

Our data met the normal requisites for logistic regression (Agresti, 1996), as evident from the absence of perfect multicollinearity and perfect separation. There were no zero cells for any categories of predictors, no standard errors larger than 2.0, and no outliers (i.e., no standardized residuals $>2.58$ at $p<.01$ ). Adding or removing alternatives in the dependent variables did not affect the odds associated with the remaining alternatives.

At each level, hierarchical regressions were conducted in three steps. In a first step, only minority (vs. nonminority) status was included to estimate gross attainment gaps. To estimate net attainment gaps, in a second step, father's education, gender, track at entry, and grade retention in primary and secondary school were added to the model. Interactions with minority status were added if significant (Table 3 ). In the final step, we added self-reported school segregation in primary and secondary school and the explanatory variables, that is, intergroup friendship and perceived teacher support, and significant interactions with minority status (Table 4). 


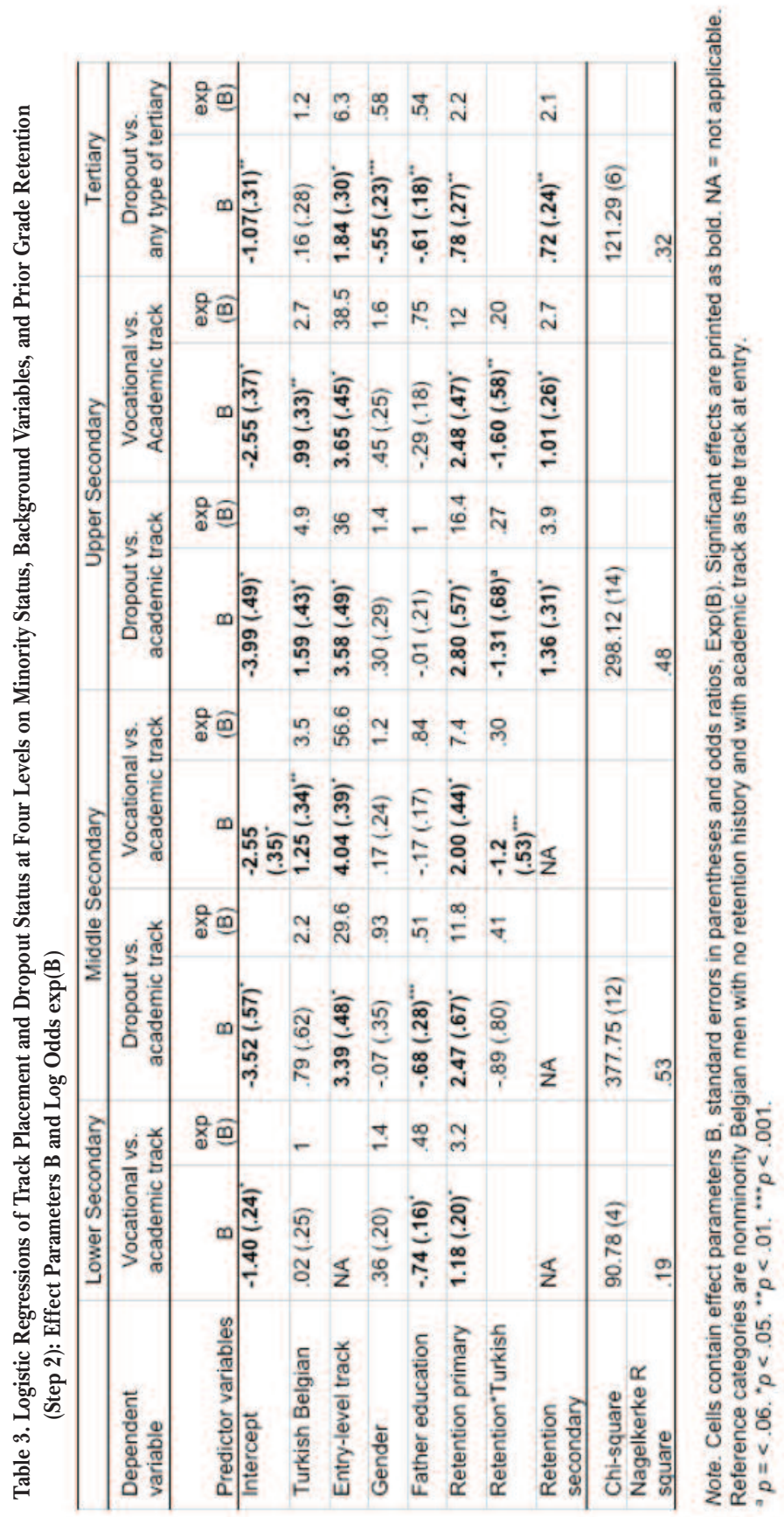




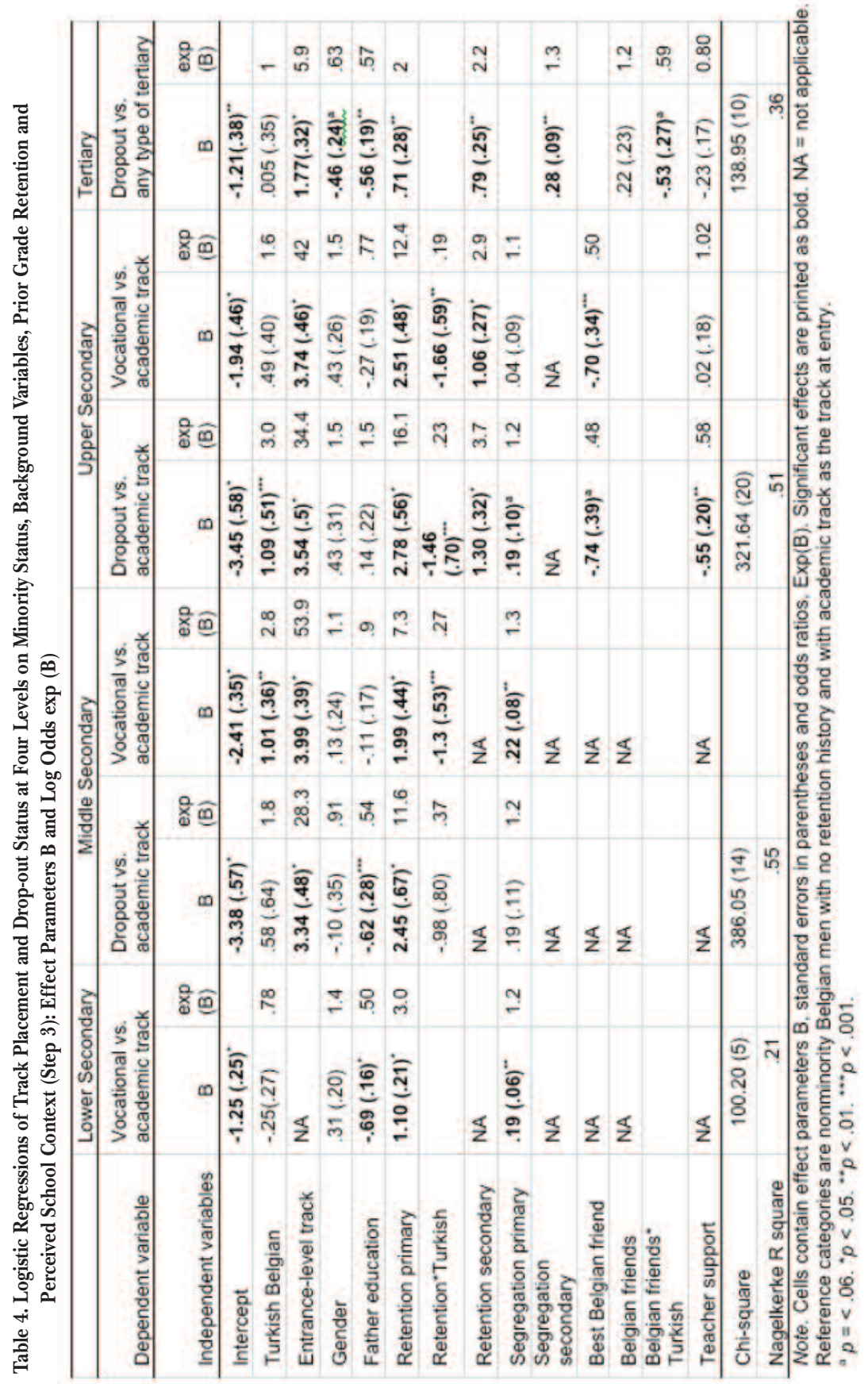


Importantly, we controlled for students' track at entry into secondary school, because it is the main determinant of track placement and dropout at later stages. Thus, we set equal their starting level to academic track. In other words, we ask, if a Turkish Belgian student starts in an academic track at the age of 12, what are the chances of staying on in school or continuing at the same level? This provides a most stringent test of the attainment gap and of the effects of perceived school environment.

\section{RESULTS}

Table 1 shows descriptive statistics for all predictors. With the exception of perceived teacher support, $t$ tests demonstrated significant differences between the two groups on continuous variables. As expected, Turkish Belgian minority students reported higher levels of segregation in primary and secondary school, with about half of the pupils, on average, of immigrant origin, than nonminority Belgian students, who reported about $25 \%$ of immigrant pupils on average. Turkish Belgian students also had significantly fewer Belgian friends, particularly best friends, than nonminority Belgians. Actually, few Belgian students had a best friend from a minority group. Moreover, Pearson ${ }^{2}$ tests showed that Turkish Belgian minority students were more likely to be retained in both primary and secondary school than nonminority students, though retention rates were also high for the nonminority students who were living in similarly disadvantaged neighborhoods.

\section{ESTIMATING THE ATTAINMENT GAPS}

Table 2 shows descriptive statistics for minority and nonminority school careers. Percentages of Turkish Belgian and Belgian students at each level document large and increasing gross attainment gaps in terms of differential track placement and dropout rates. For instance, of all Turkish Belgian students who had started secondary school in an academic track $(68 \%)$, fewer than half of those who were still in school in upper secondary completed school at the same level (37\%), as compared with $85 \%$ nonminority Belgian students who started in, and $71 \%$ who completed, academic tracks. Similar descriptive disparities were also found for dropout rates and for continuation rates into tertiary education (see Table 2).

Table 3 shows the estimates of net attainment gaps in the second step of the hierarchical regressions. A net attainment gap is indicated by a significant effect of minority status after taking into account father's education, gender, prior grade retention, and track at entry as control 
variables. Gaps at entry into secondary school and into higher education were no longer significant after controlling for father's education, gender, grade retention, and track at entry. In middle and upper secondary school, however, significant and large gaps remained between the track placement and dropout status of minority and nonminority students, as indicated by the significant net effects of minority status. In middle secondary school, minority students who had never been retained and who had started in the academic track had a chance of .20 of being in a vocational track (vs. continuing in an academic track), whereas similar nonminority students had only a chance of $.07 .{ }^{5}$ Similarly, in upper secondary school, minority students' chances of being in vocational tracks were .16, whereas the chances of similar nonminority students were only .07 (Figure 1). Finally, a significant net gap in dropout rates was found in upper secondary school. Minority students who had started in the academic track had a chance of .07 to drop out of school (vs. staying on in academic tracks), whereas similar nonminority students had a chance of only .02.

Figure 1. Vocational (vs. academic) track placement in lower, middle, and upper secondary school by minority status: Estimated probabilities for Turkish Belgian and Belgian students

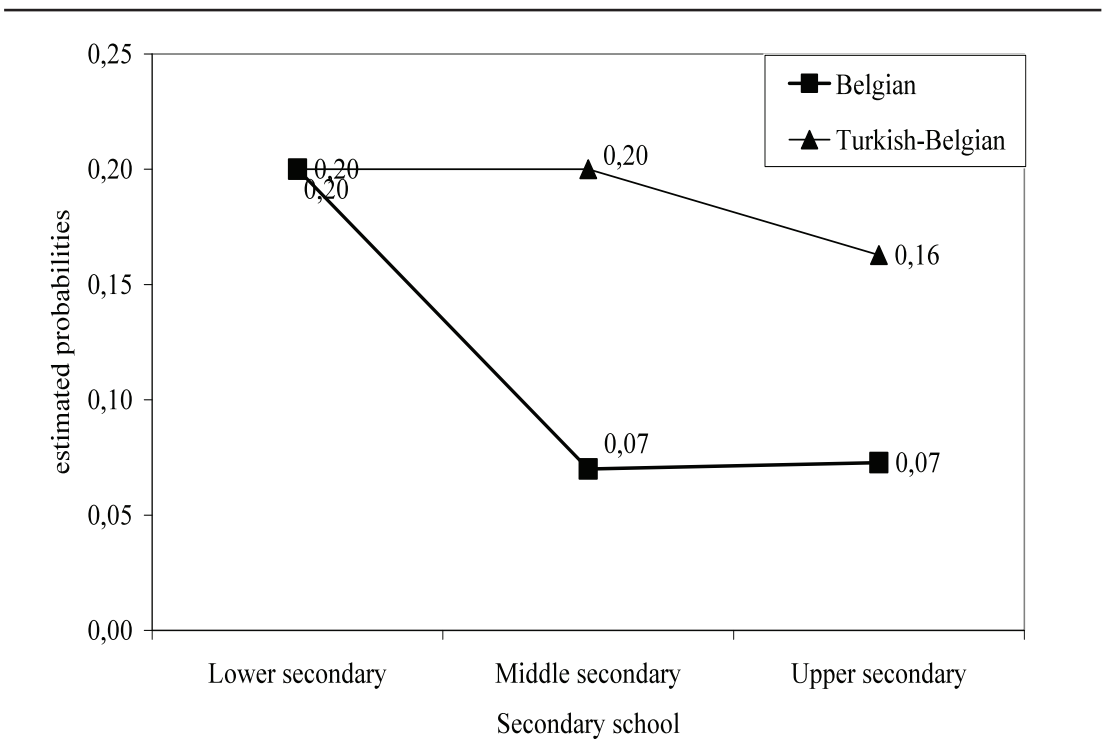

To sum up, minority and nonminority school careers showed large and increasing gross attainment gaps throughout secondary school and beyond. The net attainment gap between minority and nonminority 
students, however, is only still significant at the middle and upper secondary levels. At entry into secondary school, and again at entry into tertiary education, the attainment gap is fully explained by family resources and prior attainment as entry factors. Yet, the unexplained attainment gap widens in middle secondary and persists into upper secondary school. ${ }^{6}$ The latter findings offer clear support for the hypothesis of a persistent or widening gap between minority and nonminority attainment in the course of secondary school, net of family resources and entry levels.

\section{EXPLAINING THE GAPS}

Is the attainment gap reduced if we take into account students' experiences of the early school environment? In particular, do we find evidence of the expected protective role of positive intergroup contact with friends and teachers? To answer this question, we compared the effect sizes of minority status (Turkish Belgian) in the second step of the hierarchical regressions (Table 3) with effect sizes in a final step, when intergroup friendship, perceived teacher support, and school segregation were added to the model (Table 4 ).

As expected, the net attainment gap in middle secondary school was significantly reduced, though still significant, when we added our measures of early experiences of intergroup contact in school to the model. Specifically, minority students were 3.5 times more likely to be in vocational (vs. academic) tracks than nonminority students, controlling for student and parental background (Table 3), and they were still 2.8 times more likely to be in vocational tracks when measures of the perceived school environment were included in the model (Table 4). Also, in upper secondary school, the net attainment gap was significantly reduced. When students' prior experiences of intergroup contact with teachers and friends were included, group differences in track placement were no longer significant, and differential dropout rates were reduced from 5 times to 3 times. In line with our second hypothesis, positive intergroup experiences with teachers and peers partially or fully explained the attainment gap, indicating a unique protective role of relationship quality in the school environment.

\section{INTERGROUP FRIENDSHIP AND PERCEIVED TEACHER SUPPORT}

As shown in Table 4, students whose fathers were more highly educated were less likely to be in vocational tracks and to drop out. Women were more likely to stay on beyond secondary school than men. Students who started secondary school in vocational tracks were much more likely to 
drop out at later stages than those who started in academic tracks. Furthermore, students who had been retained in primary or secondary school were more likely than promoted students to be in vocational tracks and to leave school at an earlier age. Moreover, a significant interaction with minority status indicated that grade promotion was less predictive of later attainment for minority students than for nonminority students. In the absence of grade retention, minority students were still more likely to be in vocational tracks than nonminority students.

To identify net effects of intergroup friendship and teacher support, we controlled for school segregation. When the early school environment is more ethnically segregated, there are fewer opportunities for minority students to make nonminority Belgian friends. Similarly, regardless of the overall quality of instruction, teacher support will be more thinly spread over pupils with increasing numbers of disadvantaged minority students in more segregated schools. We found that students who attended more segregated schools were more likely to be referred to vocational training in lower and middle secondary school, to drop out in upper secondary school, and not to continue beyond secondary school.

Controlling for parental background, grade retention, initial track, and school segregation, the expected effects of intergroup friendship and perceived teacher support on later attainment were confirmed (Table 4). In upper secondary school, students whose best friend in lower secondary was of Belgian origin were 2 times less likely to be in vocational (vs. academic) tracks $(1 / .50)$ or to drop out $(1 / .48)$ than students with a best friend of immigrant origin. This effect of a nonminority Belgian best friend was equally positive for nonminority and minority students. At entry into higher education, having more nonminority Belgian friends significantly decreased the likelihood of leaving school (vs. continuing) only for Turkish Belgians. Thus, minority students who had more Belgian friends in lower secondary school were close to $11 / 2$ times more likely to continue into tertiary education $(0.22-0.53=-0.31$, $\exp (\mathrm{B})=.73$, $1 / .73=1.37$ for one unit change on a 5 -point rating scale) than minority students who reported fewer Belgian friends.

In addition, as can be seen from Table 4, perceived teacher support in lower secondary school had the expected protective effect on later attainment, in addition to intergroup friends and net of school segregation and entry factors. This effect was similar for minority and nonminority students. Specifically, in upper secondary school, students who evaluated previous support from teachers more positively were 1.7 times $(1 / .58)$ less likely to drop out (vs. completing an academic track) than students who evaluated teacher support less positively. 


\section{DISCUSSION}

Why do some disadvantaged minority students persist in academic tracks and stay on in school longer, whereas many others tend to give up and drop out? To answer this question, first we aimed to describe how the known attainment gap between minority and nonminority students, as measured by differential track placement and dropout status, unfolds over time. Next, in search of possible protective factors in the school context, this study aimed to examine the role of intergroup friendship and perceived teacher support as critical relational features of a supportive learning environment. Finally, we tested for differential effects of the early school environment on minority (vs. nonminority) school careers. The findings were largely consistent with our theoretical expectations.

Starting from a well-established yet ill-understood Turkish disadvantage in Belgium, as in other European societies (Heath et al., 2008; Phalet et al., 2007), our first hypothesis posits a persistent and widening attainment gap between minority and nonminority school careers. The Turkish Belgian case is prototypical of the schooling experiences of the children of immigrant workers in highly stratified school systems, of which the Belgian system, with its early selection and hierarchical tracking structure, is a typical example. Drawing on detailed retrospective survey data on the school careers of large random samples, our study largely confirms the first hypothesis of a persistent attainment gap. Specifically, Turkish minority students were significantly more likely not to continue in an academic track than nonminority students in middle and upper secondary school, controlling for track at entry and preceding variables. In other words, even Turkish Belgians who start secondary school in an academic track without a history of retention are more likely to be in a vocational track and to drop out at later stages in their school career than similar Belgian students.

Moreover, one should keep in mind that nonminority Belgian participants in this study were a more disadvantaged group than the average Belgian student, as they were selected from the same relatively disadvantaged neighborhoods as minority participants. Even so, we found that the minority status of second-generation Turkish students made a difference in their school careers. We concluded that our findings provide convincing evidence of a persistent and widening gap between minority and nonminority school careers in the Belgian school system.

In line with the second hypothesis on relational features of the early school environment, positive intergroup contact experiences with teachers and peers, after taking into account the negative impact of early school segregation, significantly reduced the gap, particularly in upper 
secondary school. Thus, after taking into account entry factors, students who had encountered a more favorable early school environment were significantly more likely to stay on in academic tracks and less at risk of dropping out without completing secondary school. Our third and fourth hypotheses concerned the main effects of intergroup friendship and perceived teacher support on later attainment and possible interactions with minority status. First, perceived teacher support was revealed as a general protective factor: Students who perceived more support from teachers in lower secondary school did better in upper secondary, regardless of minority status. Specifically, students who perceived more support from teachers in lower secondary school had lower dropout risks-though not higher chances of continuing in academic rather than vocational tracks-than their peers who perceived less support from teachers early on. This finding is in line with extensive evidence of the general importance of supportive student-teacher relationships in securing children's school engagement (Birch \& Ladd, 1997). Second, the positive effects of nonminority friends were mostly specific to minority students. For example, Turkish Belgian minority students who reported more Belgian friends were $11 / 2$ times more likely to continue into higher education than those with fewer or no Belgian friends. At upper secondary level, however, both Turkish Belgian and nonminority Belgian students who had nonminority best friends had higher chances of being in academic education. We should be cautious in interpreting this generic "best friend" effect, though, because most majority-group students in our study had Belgian best friends. The few Belgian students with a minority best friend might have been a marginal and less successful group.

Overall, our findings demonstrate the key role of teacher and peer relationship quality in supporting minority (and nonminority) attainment and in reducing the attainment gap. More generally, the findings resonate with a heuristic approach from identity safety (vs. threat) in culturally diverse school settings, given that it was derived from social identity theory and from robust evidence of so-called stereotype threat. Identity threat arises when disadvantaged minority students constitute a numerical minority in academic or higher forms of education, when they experience direct or vicarious discrimination in school, or when they face negative stereotypes about the academic competence of their group. Accordingly, converging longitudinal and experimental evidence linking perceived discrimination and stereotyping to performance deficits has demonstrated that identity threat is detrimental for the school engagement and performance of minority students. On the positive side, our findings stress the importance of intergroup relationship quality for 
social identity protection in an identity-safe school environment (Derks et al., 2007; Purdie-Vaughns et al., 2008). To the extent that the quality of intergroup relations with teachers and peers communicates to minority students that their identity is valued in school (Abrams et al., 2006), intergroup friends and supportive teachers should effectively protect them from identity threat in school. Consequently, intergroup friends and teachers should improve sustained school engagement through enhancing feelings of belonging and acceptance, and thus reducing threat, in minority students. Other parallel lines of research have converged on similar expectations of beneficial effects from positive intergroup contact. Thus, acculturation studies have related intergroup friendship to enhanced culture learning (Berry et al., 2006), and migration sociologists have highlighted the value of intergroup social ties as conduits to bridging social capital (Heath et al., 2008). Our findings lay the ground for future research that should further disentangle the mediating processes that connect the quality of intergroup relations in school to reduced educational inequalities.

Importantly, our findings should be contextualized in light of the structural characteristics of educational systems as institutional settings, which are at the basis of exclusionary tracking practices and which produce varying levels of vertical school segregation. In the Belgian case, as in other European school systems such as the Dutch and German systems, our findings show that hierarchical tracking structures perpetuate and enlarge the extant educational inequality that is due to early timing and irreversibility of selection into different tracks, given that social origin is more strongly associated with educational attainment at younger ages (Breen \& Jonsson, 2005). In addition to formal institutional structures, the public climate in Belgium, as in many other European societies, is characterized by pervasive public prejudice and discrimination against immigrant workers and their children. Against the background of an exclusionary institutional and intergroup context, then, our study shows that the presence of positive contact experiences-however restrictedmakes a significant difference in minority school careers.

Finally, this study has some limitations. Whereas retrospective data on behavioral and factual questions yield reasonably reliable information (Blossfeld \& Rohwer, 2002), such as self-reported dropout status and track placement, prospective longitudinal data would strengthen the empirical case for causal effects of intergroup friendship and teacher support on attainment. Because we have to rely on retrospective study, we cannot rule out the possibility that, for instance, students who dropped out reported more negative student-teacher relations in retrospect than students who stayed on in school longer. Reverse causation seems less 
plausible, however, in light of consistent longitudinal findings of the long-term impact of perceived teacher support on educational outcomes (Buyse et al., 2009; DiLalla et al., 2004; Entwisle \& Hayduk, 1988; Hamre \& Pianta, 2001). Moreover, our analyses controlled for track placement at entry into secondary school as a proxy for previously demonstrated school performance, which makes reverse causation less likely. Finally, future studies should include test performance as an objective measure of academic achievement, in addition to attainment.

To conclude, this research sheds new light on the quasi-absence of Turkish Belgians from Belgian universities, documenting the cumulative effects of down- and out-streaming in the course of secondary school. It contributes to existing research on minority school careers and intergroup relations by showing the effects of positive intergroup contact on performance outcomes in schools as intergroup settings. Our results strongly suggest that culturally diverse schools should encourage social mixing across group boundaries, with a view to effectively supporting minority identities and success. Finally, more highly attaining minority and nonminority students alike experienced more supportive relationships with teachers in their early school careers. This finding confirms the importance of student-teacher relationship quality in terms of its long-term impact on sustained school engagement and success at later stages of the school career.

Notes

1. In the remainder of this article, we will use the term minority to refer narrowly to the local-born children of immigrant workers in the Northwest European context of labor migration.

2. In the absence of a standardized grading system in Europe, track placement is the closest proxy of school performance. Tracks signal one's position in hierarchical school systems in terms of past performance, and they strongly predict final qualifications.

3. The gender by age by residential area distribution of the Turkish Belgian sample did not deviate from the population distribution. Hence, the nonminority comparison sample was reweighed toward the Turkish Belgian sampling distribution.

4. In middle secondary, 4 cases were dropped because of missing values, and 7 because they left after primary school. In upper secondary, 55 cases were dropped because they had already left school, and 47 because of missing values. At entry into tertiary, 148 cases had already left school before graduating from secondary school, and 43 cases had missing values, resulting in a sample of 470 cases.

5. Estimated response probabilities were calculated according to Agresti (1996). For instance, in middle secondary, the estimated probability of being in a vocational track versus an academic track for Belgians who started out in the academic track and with no retention history was $.07=[\exp (-2.55)] /[1+\exp (-3.52)+\exp (-2.55)]$.

6. A widening attainment gap requires a significant effect parameter at each subsequent level rather than increasing sizes of parameter estimates over time, given that samples are increasingly selective at each subsequent level. 


\section{References}

Abrams, D., Eller, A., \& Bryant, J. (2006). An age apart: The effects of intergenerational contact and stereotype threat on performance and intergroup bias. Psychology and Aging, 21, 691-702.

Agresti, A. (1996). An introduction to categorical data analysis. New York: Wiley.

Baysu, G., Phalet, K., \& Brown, R. (2011). "Dual” identity as a two edged sword: Identity threat and minority school performance. Social Psychology Quarterly, 74(2), 121-143.

Benner, A. D., \& Kim, S. Y. (2009). Experiences of discrimination among Chinese-American adolescents and the consequences for socio-emotional and academic development. Developmental Psychology, 45, 1682-1694.

Berry, J. W., Phinney, S. P., Sam, D. L., \& Vedder, P. (Eds.). (2006). Immigrant youth in cultural transition: Acculturation, identity, and adaptation across national contexts. Mahwah, NJ: Erlbaum.

Birch, S. H., \& Ladd, G. W (1997). The teacher-child relationship and children's early school adjustment. Journal of School Psychology, 35, 61-79.

Blossfeld, H. P., \& Rohwer, G. (2002). Techniques of event history modeling: New approaches to causal analysis (2nd ed.). Mahwah, NJ: Erlbaum.

Breen, R., \& Jonsson J. O. (2000). Analyzing educational careers: A multinomial transition model. American Sociological Review, 65, 754-772.

Breen, R., \& Jonsson, J. O. (2005). Inequality of opportunity in comparative perspective: Recent research on educational attainment and social mobility. Annual Review of Sociology, 31, 223-244.

Brown, R., \& Hewstone, M. (2005). An integrative theory of intergroup contact. Advances in Experimental Social Psychology, 37, 255-343.

Buyse, E., Verschueren, K., Verachtert, P., \& Van Damme, J. (2009). Predicting school adjustment in early elementary school: Impact of teacher-child relationship quality and relational classroom climate. Elementary School Journal, 110, 119-141.

Dauber, S., Alexander, K. L., \& Entwisle, D. R. (1996). Tracking and transitions through the middle grades. Sociology of Education, 69, 290-307.

Derks, B., van Laar, C., \& Ellemers, N. (2007). The beneficial effects of social identity protection on the performance motivation of members of devalued groups. Social Issues and Policy Review, 1, 217-256.

DiLalla, L. F., Marcus, J. L., \& Wright-Phillips, M. (2004). Longitudinal effects of preschool behavioral styles on early adolescent school performance. Journal of School Psychology, 42, 385-401.

Entwisle, D. R., \& Hayduk, L. A. (1988). Lasting effects of elementary school. Sociology of Education, 61, 147-159.

Goodenow, C. (1993). Classroom belonging among early adolescent students. Journal of Early Adolescence, 13, 21-43.

Hallinan, M. T., \& Williams, R. A. (1990). Students' characteristics and the peer-influence process. Sociology of Education, 63, 122-132.

Hamre, B. K., \& Pianta, R. C. (2001). Early teacher-child relationships and the trajectory of children's school outcomes through eighth grade. Child Development, 72, 625-638.

Han, W. (2008). The academic trajectories of children of immigrants and their school environments. Developmental Psychology, 44, 1572-1590.

Harris, D. N. (2010). How do school peers influence student educational outcomes? Theory and evidence from economics and other social sciences. Teachers College Record, 112, 1163-1197. 
Heath, A., Rothon, C., \& Kilpi, E. (2008). The second generation in Western Europe: Education, unemployment, and occupational attainment. Annual Review of Sociology, 34, 211-235.

Hughes, J. N., Cavell, T. A., \& Willson, V. (2001). Further evidence of the developmental significance of the student-teacher relationship. Journal of School Psychology, 39, 289-302.

Kalmijn, M., \& Kraaykamp, G. (2003). Dropout and downward mobility in the educational careers: An event-history analysis of ethnic schooling differences in The Netherlands. Educational Research and Evaluation, 9, 265-287.

Kalter, F. (2006). Auf der suche nach einer erklärung für die spezifischen arbeitsmarktnachteile von jugendlichen Türkischer herkunft [In search of an explanation for the specific labor market disadvantages of second-generation Turkish migrant children]. Zeitschrift für Soziologie 35, 144-160.

Kao, G., \& Thompson, J.S. (2003). Racial and ethnic stratification in educational achievement and attainment. Annual Review of Sociology, 29, 417-442.

Kleinpenning, G., \& Hagendoorn, L. (1991). Contextual aspects of ethnic stereotypes and interethnic evaluations. European Journal of Social Psychology, 21, 331-348.

Massey, D., \& Fischer, M. (2005). Stereotype threat and academic performance: New findings from a racially diverse sample of college freshmen. Du Bois Review, 2, 45-67.

Moller, S., Stearns, E., Blau, J., \& Land, K. (2006). Smooth and rough roads to academic achievement: Retention and race/class disparities in high school. Social Science Research, $35,157-180$.

Murray, C. (2009). Parent and teacher relationships as predictors of school engagement and functioning among low-income urban youth. Journal of Early Adolescence 29, 376-404.

Murray, C., \& Greenberg, M. T. (2000). Children's relationship with teachers and bonds with school an investigation of patterns and correlates in middle childhood. Journal of School Psychology, 38, 423-445.

Organisation for Economic Co-operation and Development. (2006). Where immigrant students succeed: A comparative review of performance and engagement in PISA. Retrieved from http://www.oecd.org/dataoecd/2/38/36664934.pdf

Pettigrew, T. F., \& Tropp, L. R. (2006). A meta-analytic test of intergroup contact theory. Journal of Personality and Social Psychology, 90, 751-783.

Phalet, K., Deboosere, P., \& Bastiaenssen, V. (2007). Old and new inequalities in educational attainment: Ethnic minorities in the Belgian census 1991-2001. Ethnicities, 7, 390-415.

Phalet, K., \& Heath, A. (2011). Ethnic community, urban economy and second-generation attainment: Turkish disadvantage in Brussels-Belgium. In R. Alba \& M. Waters (Eds.), New dimensions of diversity: The children of immigrants in North America and Western Europe. New York: New York University Press.

Phelan, P., Davidson, A. L., \& Yu, H. G (1998). Adolescents' worlds: Negotiating family, peers, and school. New York: Teachers College Press.

Portes, A. (1998). Social capital: Its origins and applications in modern sociology. Annual Review of Sociology, 24, 1-24.

Purdie-Vaughns, V., Steele, C. M., Davies, P. G., Ditlmann, R., \& Randall-Crosby, J. (2008). Social identity contingencies: How diversity cues signal threat or safety for African Americans in mainstream institutions. Journal of Personality and Social Psychology, 94, $615-630$.

Rosenthal, H. E. S., Crisp, R. J., \& Suen, M.W. (2007). Improving performance expectancies in stereotypic domains: Task relevance and the reduction of stereotype threat. European Journal of Social Psychology, 37, 586-597. 
Ryan, A. M. (2001). The peer group as a context for the development of young adolescent motivation and achievement. Child Development, 72, 1135-1150.

Shook, N. J., \& Fazio, R. H. (2008). Roommate relationships: A comparison of interracial and same-race living situations. Group Processes and Intergroup Relations, 11, 425-437.

Steele, C. M. (1997). A threat in the air: How stereotypes shape intellectual identity and performance. American Psychologist, 52, 613-629.

Steele, C. M., Spencer, S. J., \& Aronson, J. (2002). Contending with group image: The psychology of stereotype and social identity threat. Advances in Experimental Social Psychology, 34, 379-440.

Suárez-Orozco, C., Pimentel, A., \& Martin, M. (2009). The significance of relationships: Academic engagement and achievement among immigrant newcomer youth. Teachers College Record, 111, 712-749.

Tajfel, H., \& Turner, J. (1986). The social identity theory of intergroup behavior. In S. Worchel \& W. Austin (Eds.), Psychology of intergroup relations (pp. 7-24). Chicago: NelsonHall.

TIES [The Integration of the European Second Generation]. (2008). Belgium [Data file and codebook]. Leuven, Belgium: Ceso and CSCP, University of Leuven.

Verkuyten, M., \& Thijs, J. (2004). Psychological disengagement from the academic domain among ethnic minority adolescents in The Netherlands. British Journal of Educational Psychology, 74, 109-125.

Walberg, H. J., Fraser, B. J., \& Welch, W. W. (1986). A test of a model of educational productivity among senior high school students. Journal of Educational Research, 79, 133-139.

Walton, G. M., \& Cohen, G. L. (2007). A question of belonging: Race, social fit, and achievement. Journal of Personality and Social Psychology, 92, 82-96.

Ward, C., Bochner, S., \& Furnham, A. (2001). The psychology of culture shock (2nd ed.). London: Routledge.

Wentzel, K. R., \& Wigfield, A. (2007). Introduction to motivation at school: Interventions that work. Educational Psychologist, 42, 261-271.

GÜLSELI BAYSU is Experienced Researcher at the Center for Social and Cultural Psychology, Department of Psychology, University of Leuven, Belgium. She obtained her PhD in psychology at Middle East Technical University, Turkey. Her current research examines the role of segregation, discrimination, stereotype threat, intergroup friendship, and bicultural identity in minority school careers. She has recently published on bicultural identity.

KAREN PHALET is professor at the Center for Social and Cultural Psychology, Department of Psychology, University of Leuven, Belgium. Her main research interests are acculturation, identity, inequality, and conflict in intergroup relations. She has recently published on religious identity and school adjustment of the European second generation. 